\title{
La protéine trans-activatrice Tat de HIV-1 : cible potentielle pour les agents antiviraux
}

Le virus d'immunodéficience humaine de type I (HIV-l) appartient à la famille des lentivirus. Ces rétrovirus non transformants causent une dégénérescence progressive des systèmes nerveux et immunitaires. Outre l'absence d'activité cancérigène, les lentivirus se distinguent des rétrovirus transformants au niveau de leur organisation génétique. En effet, leur génome contient, en plus des gènes gag, pol et $e n v$, de petits cadres de lecture qui codent pour les protéines régulatrices de l'expression génique virale.

La réplication de HIV-l nécessite la présence de deux de ces protéines régulatrices virales: $\operatorname{Rev}$ (voir $\mathrm{m} / \mathrm{s}$ $n^{\circ} 6$, vol. 5, p. 423) et Tat. La protéine Tat produit une activation en trans de l'expression génique virale. La séquence d'ADN requise pour la trans-activation par Tat (cette séquence est appelée TAR) se situe au niveau de la longue répétition terminale (LTR, long terminal repeat) de HIV-l. Comme dans le cas des autres rétrovirus, c'est au niveau de la séquence LTR que sont contenus les éléments de régulation de l'expression génique virale tels le promoteur, l'activateur de transcription (enhancer) et le site de polyadénylation. L'élucidation des mécanismes qui régissent la transactivation par Tat est essentielle à la compréhension du contrôle du cycle de réplication de HIV-l et ainsi ouvre la voie à de nouvelles stratégies thérapeutiques. En effet, le rôle primordial de Tat dans l'expression génique virale suggère que cette protéine régulatrice pourrait servir de cible pour le développement d'agents antiviraux.
Le(s) mécanisme(s) de trans-activation. Bien que la nature du (ou des) mécanisme(s) de trans-activation par Tat ait fait l'objet de plusieurs études, elle n'en demeure pas moins controversée. L'approche expérimentale a été très simple. Des cellules sont co-transfectées avec un plasmide exprimant le gène tat et un plasmide exprimant un gène indicateur (tel que le gène de l'enzyme bactérienne chloramphénicol acétyltransférase [CAT] ou interleukine-2) sous le contrôle de la séquence LTR qui contient la région TAR. Le degré d'expression du gène indicateur ( $\mathrm{au}$ niveau transcriptionnel et post-transcriptionnel) est mesuré et comparé à celui en absence de Tat. Plusieurs mécanismes de trans-activation ont été suggérés : (a) l'augmentation du taux d'initiation de la transcription [1] ; (b) la prévention d'une terminaison précoce de la transcription (dit antiterminaison de la transcription) [2]; (c) l'augmentation de la stabilité des ARNm [3]; (d) l'augmentation de l'efficacité traductionnelle des ARNm [4-6].

L'importance relative de chacun des mécanismes décrits ci-dessus est probablement influencée par la stratégie expérimentale : type de cellule transfectée, nature des plasmides utilisés et/ou mode de transfection. Qu'une seule protéine puisse accomplir toutes ces fonctions est peu probable. Cependant, il n'est pas exclu que la trans-activation virale nécessite l'interaction de Tat avec des protéines cellulaires.

La séquence de reconnaissance TAR. Initialement, la région requise pour la trans-activation par Tat a été localisée entre les nucléotides -17 et +80 de la séquence LTR (+ 1 étant le site d'initiation de la transcription). Les séquences minimales requises pour la trans-activation ont été définies entre les nucléotides +18 et +44 [7] Toutefois, il semble que des éléments structuraux en dehors de cette région contribuent aussi à la trans-activation [8]. La région TAR n'est fonctionnelle que si elle est positionnée correctement et dans la bonne orientation. Elle est présente dans la région non codante de tous les ARNm viraux et peut former une structure tige-boucle (aussi appelée structure en épingle à cheveux) entre les nucléotides +1 et +60 [3]. Cette structure pourrait être impliquée dans le contrôle de la traduction des ARNm viraux [9, 10]. De plus, elle est importante pour la trans-activation. La séquence nucléotidique dans la boucle [11] ainsi que la présence d'une petite boucle secondaire de trois nucléotides entre la position +23 et +25 [8] sont essentielles pour la fonction de TAR. Par ailleurs, la séquence primaire de la tige ne semble pas importante pour la transactivation, puisque des mutations qui reconstituent l'appariement des bases n'affectent pas celle-ci [8]. Seule la présence d'une tige intacte serait nécessaire pour maintenir les deux boucles dans une configuration qui favorise l'interaction avec des facteurs cellulaires ou viraux (figure 1). Plusieurs facteurs cellulaires interagissant avec l'ADN TAR et l'ARN TAR ont été identifiés [12, 13]. De plus, deux groupes de chercheurs ont annoncé, lors de la $5^{\mathrm{e}}$ conférence internationale sur le SIDA à Montréal, que la protéine Tat se lie directement à l'ARN TAR. L'importance 


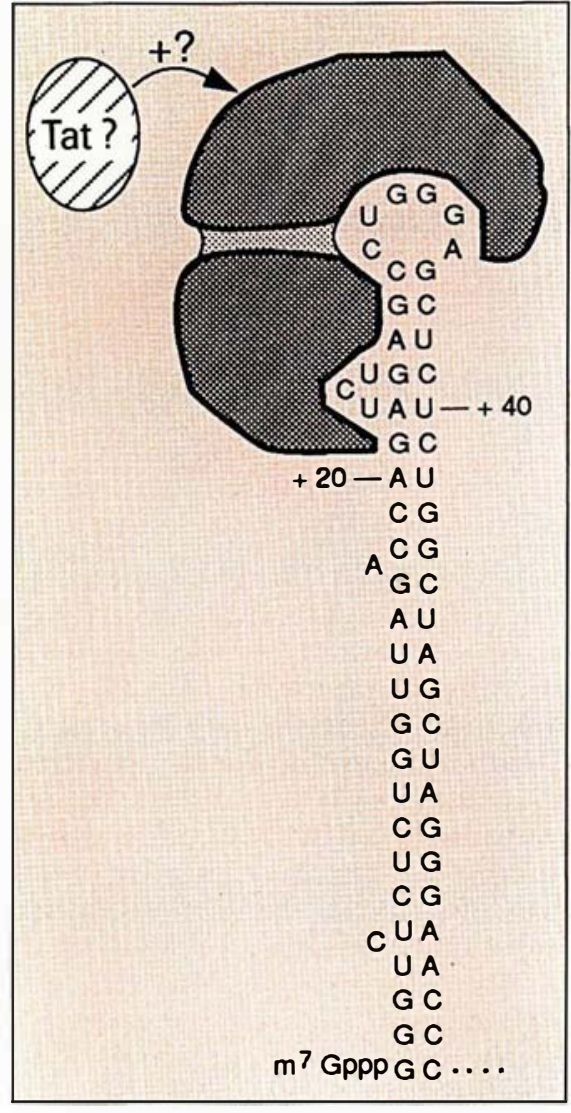

Figure 1. Structure tige-boucle adoptée par I'ARN de la région TAR de HIV-1. Des études antérieures ont démontré que la grande boucle $(+30$ à +35$)$ et la boucle secondaire $(+23 a+25)$ sont requises pour l'activité trans-activatrice de Tat. Ces deux structures pourraient servir de site d'interaction pour une ou plusieurs protéines jouant un rôle dans la transactivation. Tat pourrait se lier directement à I'ARN TAR ou faciliter l'interaction de protéines cellulaires.

de ces interactions protéines-acides nucléiques sur la trans-activation reste cependant à évaluer.

La protéine trans-activatrice Tat. Tat est une protéine nucléaire constituée de 86 acides aminés $\left(M_{r} 14 \mathrm{kDa}\right)$ et codée par deux exons du génome viral. Seules les séquences du premier exon sont requises pour la transactivation. Récemment, il a été démontré que la protéine purifiée ou synthétisée chimiquement peut, lorsqu'elle est ajoutée au milieu de culture, entrer dans les cellules et transactiver l'expression de gènes possé- approche expérimentale a permis l'identification des séquences minimales nécessaires pour la fonction de Tat. La région $\mathbf{N}$-terminale (acides aminés 1 à 37) contient sept cystéines qui se lient à des métaux divalents tels que le zinc ou le cadmium. Cette région est importante pour le repliement de la protéine et participe à la dimérisation de Tat. La deuxième région (acides aminés 38 à 48) a été définie comme la région requise pour la trans-activation. En effet, des peptides contenant des mutations dans la deuxième région agissent comme répresseurs trans-dominants de la fonction Tat [16]. Il a été suggéré que ces peptides bloquent l'interaction de la protéine Tat avec une cible de nature protéique ou nucléique encore non identifiée. La troisième région (acides aminés 49 à 57) contient huit lysines ou arginines et est donc extrêmement basique. Elle est requise pour la localisation de Tat dans le noyau. La quatrième région (acides aminés 58 à 72 ) est riche en glutamine et augmente l'activité trans-activatrice.

Conclusion : Tat joue un rôle essentiel dans la réplication de HIV-l. Son mécanisme d'action est encore controversé. L'identification du (ou des) mécanisme(s) impliqués devra probablement attendre le développement d'une approche expérimentale in vitro reproduisant la trans-activation par Tat. La protéine Tat peut être subdivisée en quatre régions: seule la deuxième (acides aminés 38 à 48) est nécessaire à l'activité transactivatrice. La découverte récente de peptides agissant comme répresseurs trans-dominants de la fonction Tat ouvre la porte à de nouvelles stratégies thérapeutiques. Le développement d'agents antiviraux qui, comme ces répresseurs trans-dominants, bloquent l'interaction de la protéine Tat avec une cible encore inconnue offre un nouvel espoir dans la lutte contre le SIDA

\section{Sophie Roy \\ Charles Goyer}

Neil T. Parkin

Université Mc Gill, département de biochimie, Montréal, Québec, Canada.

\section{RÉFÉRENCES}

1. Jeang KT, Shank PR, Kumar A. Transcriptional activation of homologous viral long terminal repeats by the human immunodeficiency virus type I or the human T-cel leukemia virus type I Tat proteins occurs in the absence of de novo protein synthesis. Proc Natl Acad Sci USA 1988; 85 : 8291-5.

2. Kao SY, Calman AF, Luciw PA, Peterlin BM. Anti-termination of transcription within the long terminal repeat of HIV-l by tat gene product. Nature 1987 ; 330 : 489-93. 3. Muesing MA, Smith DH, Capon DJ. Regulation of mRNA accumulation by a human immunodeficiency virus transactivator protein. Cell $1987 ; 48: 691-701$.

4. Cullen B. Transactivation of human immunodeficiency virus occurs via a bimodal mechanism. Cell 1986 ; 46 : 973-82.

5. Braddock M, Chambers A, Wilson W, et al. HIV-1 Tat «activates » presynthesized RNA in the nucleus. Cell $1989 ; 58: 269-79$.

6. Rosen CA, Sodroski JG, Goh WC, Dayton AI, Lippke J, Haseltine WA. Post-transcriptional regulation accounts for the transactivation of the human T-lymphotropic virus type III. Nature 1986 ; 319 : 555-9.

7. Garcia JA, Harrich D, Soultanakis E, Wu F, Mitsuyasu R, Gaynor RB. Human immunodeficiency virus type 1 LTR TATA and TAR region sequences required for transcriptional regulation. EMBO J 1989; 8 : 76578.

8. Roy S, Parkin NT, Rosen CA, Itovitch J, Sonenberg N. Structural requirements for transactivation by $\mathrm{Tat}$ : importance of base pairing, loop sequence, and bulges in the TAR region. Manuscrit en préparation.

9. Parkin NT, CohenEA, DarveauA Rosen C, Haseltine W, Sonenberg N. Mutational analysis of the $5^{\prime}$ non-coding region of human immunodeficiency virus type 1 effects of secondary structure on translation EMBO J 1988; 7 : 2831-7.

10. Edery I, Petryshyn R, Sonenberg N. Activation of double-stranded RNA-dependen kinase (dsl) by the TAR region of HIV-l mRNA : a novel translational control mechanism. Cell 1989 ; 56 : 303-12.

11. Feng S, Holland EC. HIV-1 tat trans-activation requires the loop sequence within TAR. Nature 1988 ; 334 : 165-7.

12. Jones KA, Luciw PA, Duchange N. Structural arrangements of transcription control domains within the 5'-untranslated leader regions of the HIV-1 and HIV-2 promoters. Genes Dev 1988; 2 : 1101-14.

13. Gaynor RB, Soultanakis E, Kuwabara M Garcia JA, Sigman DS. Specific binding of a HeLa cell nuclear protein to RNA sequences in the human immunodeficiency virus transactivating region. Proc Natl Acad Sci USA 1989 ; 86 : 4858-62

14. Frankel AD, Pabo CO. Cellular uptake of the tat protein from human immunodeficiency virus. Cell $1988 ; 55$ : 1189-93.

15. Green M, Loewenstein PM. Autonomous functional domains of chemically synthesized human immunodeficiency virus tat transactivator protein. Cell $1988 ; 55$ : 1179-88.

16. Green $M$, Ishino $M$, Loewenstein PM Mutational analysis of HIV-l tat minimal domain peptides: identification of transdominant mutants that suppress HIV-LTR driven gene expression. Cell 1989 ; 58 : 215-23. 